WADD TECHNICAL REPORT 60-384

\title{
NITROGEN TETROXIDE CORROSION STUDIES
}

\author{
C. W. Alley \\ A. W. Hayford \\ H. F. Scott, Jr.
}

Nitrogen Division, Allied Chemical Corporation

JULY 1960

Materials Central

Contract No. AF 33(616)-6568

Project No. 7312

\section{WRIGHT AIR DEVELOPMENT DIVISION \\ AIR RESEARCH AND DEVELOPMENT COMMAND UNITED STATES AIR FORCE \\ WRIGHT-PATTERSON AIR FORCE BASE, OHIO}

400 - November $1960-7-363$ 